\title{
DIURNAL VARIATION IN THE RESPIRATION OF RECONSTRUCTED SOIL MASSES AND HYDROTHERMAL INFLUENCING FACTORS
}

\author{
LEI, N. ${ }^{1,2,3,4,5^{*}}-$ SUN, Z. H. ${ }^{1,3,4,5}-$ WANG, H. Y. ${ }^{1,3,4,5}-$ DONG, Q. G. ${ }^{1,3,4,5}$

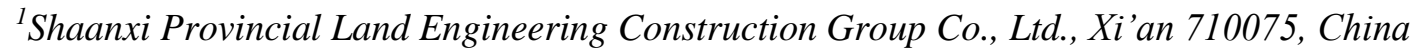 \\ ${ }^{2}$ Institute of Soil and Water Conservation, Northwest A\&F University, Yangling Shaanxi 712100, \\ China
}

${ }^{3}$ Institute of Land Engineering and Technology, Shaanxi Provincial Land Engineering Construction Group Co., Ltd., Xi'an 710075, China

${ }^{4}$ Key Laboratory of Degraded and Unused Land Consolidation Engineering, the Ministry of Natural Resources, Xi'an 710075, China

${ }^{5}$ Shaanxi Provincial Land Consolidation Engineering Technology Research Center, Xi'an 710075, China

${ }^{*}$ Corresponding author

e-mail: linye2323@126.com; phone: +86-029-8862-5020

(Received 21 ${ }^{\text {st }}$ Dec 2019; accepted 6 ${ }^{\text {th }}$ May 2020)

\begin{abstract}
Diurnal variation characteristics in the respiration of four reconstructed soil masses in a barren gravel land were monitored using soil carbon flux measurement system. The results showed that (1) the variation had a single-peak curve, with the lowest value recorded at 6:00 or 20:00, and the highest value at 10:00, 12:00, or 14:00. The soil respiration values of the four reconstructed soil masses reached the maximum and minimum in August and January, respectively. (2) The variation can be explained by a single factor of soil temperature (i.e., index model), soil volumetric water content (i.e., quadratic model), or both factors (i.e., power-index model). However, the explanatory power was different, i.e., generally higher than $50.0 \%$ for the two-factor model, and the interpretation ability of temperature was significantly higher than that of water for the single-factor model. (3) The three-model fitting of the hydrothermal factors and reconstructed soil mass, with the added meteorite, showed that these factors had the lowest ability to explain the diurnal variations in soil respiration. In contrast, the quadratic curve model of the soil volume water content and reconstructed soil mass, with the added shale, had the highest ability to interpret the diurnal variation in soil respiration.
\end{abstract}

Keywords: diurnal variation, soil respiration, hydrothermal factors, soil temperature, soil moisture

\section{Introduction}

Soil respiration affects the acceleration of climate change due to its role in regulating the carbon cycle of various ecosystems. Therefore, soil respiration characteristics of different types of ecosystems (Lai et al., 2012; Yu et al., 2019), land use (Hu et al., 2018), regions (Goldberg et al., 2017; Li et al., 2018) and degraded land (Rey et al., 2010) have been studied. Research generally began with a minimum time scale study of diurnal changes in soil respiration. The study on the diurnal variation of soil respiration can provide supporting data for further understanding of the seasonal changes in soil respiration and its causative factors, as well as an accurate accounting of regional carbon emissions. Studies (Wang et al., 2007; Zhou et al., 2017) found that the temperature and moisture were the critical environmental factors for the diurnal 
changes in the soil respiration. A significant correlation was found between soil respiration rate and atmospheric temperature or soil temperature at different depths. Generally, the relationship between both the parameters can be described statistically through approaches, such as linear and exponential functions (Meyer et al., 2018; Sun et al., 2019).

At present, land remediation has evolved from simple land levelling and supporting facilities construction to soil reconstruction in China. It aims to build high-quality cultivated land with high nutrient content and good soil structure through remediation. Huayin, Baoji and other places of Shaanxi, China, there are a large number of barren gravel lands. The existing projects have carried out soil masses reconstruction by adding different soil materials and improved materials. The reconstructed soil masses will become the main direction of land remediation in the future and an important means to supplement cultivated land resources. At the same time, the soil masses reconstruction changed the underlying surface conditions of the area, resulting in changes in the soil respiration of the newly formed soil masses, which in turn affected the regional climate, but at this stage, the study of respiration of reconstructed soil masses is still rare. In this study, four reconstructed soils added with meteorite, shale, sand and soft rock were selected as research objects. The typical day was selected every month, and soil carbon flux measurement system was used to observe soil respiration and its components. At the same time, hydrothermal factors were measured to find out the diurnal variation characteristics of respiration and hydrothermal influence factors of four reconstructed soils and their relationship. The study would provide a scientific reference and data support for the accurate assessment of regional $\mathrm{CO}_{2}$ emissions and the development of reasonable $\mathrm{CO}_{2}$ reduction measures.

\section{Materials and methods}

\section{Overview of test plots}

The test plot is located in Shangwang Village, Tangyu Town, Meixian County, Baoji City, Shaanxi Province $\left(107^{\circ} 53^{\prime} 50^{\prime \prime} \mathrm{E}, 34^{\circ} 8^{\prime} 33^{\prime \prime} \mathrm{N}\right)$, and a demonstration area for the barren gravel land remediation project. The total area is $8.00 \mathrm{hm}^{2}$, and the newly added cultivated land is $6.80 \mathrm{hm}^{2}$. Four materials of soft rock, sand, shale, and meteorite were selected, crushed through a $10 \mathrm{~mm}$ sieve, disinfected, sterilized, and mixed with the constructed soil source to form a mixed layer $(30 \mathrm{~cm})$ of meteorite, shale, sand and meteorite, and soil. Lou soil, which was the local common soil type, was used for construction. Finally, four reconstituted soil masses were formed, i.e., gravel + meteorite + lou, gravel + shale + lou, gravel + sand + lou, and gravel + soft rock + lou soil types (hereinafter referred to as meteorite, shale, sand, and soft rock reconstituted soil masses) long-term positioning test. The dosage of meteorite, shale, sand, and soft rock was $1 \times 10^{-3} \mathrm{~m}^{3} / \mathrm{m}^{2}$. The dimensions of all test plots were $20 \times 30 \mathrm{~m}^{2}$.

\section{Test methods}

From November 2017 to October 2018, all the soil respiration rings of four test plots were measured on the typical day each month. The measurement time per typical day was at 6:00, 8:00, 10:00, 12:00, 14:00, 16:00, 18:00, 20:00, and the time interval was 2 hours. Soil respiration measurements were performed using a soil carbon flux measurement system (LI-8100, LI-COR Biosciences, Lincoln, NE, USA) equipped 
with a soil respiration chamber and equipped with an auxiliary sensor connected to the main unit. The sensor can be connected to up to 4 thermocouples ( 3 input voltages and 1 soil water content channel). When measuring soil respiration, the respiration chamber was placed on the buried soil respiration ring to ensure that the connection between the respiration ring and the soil respiration chamber was sealed, and the electronic temperature probe were connected to the sensor. Moreover, the time domain reflectometry probes were inserted vertically into the soil near each respiration ring to measure soil carbon flux, soil temperature at $5 \mathrm{~cm}$, and water content at $10 \mathrm{~cm}$. Each soil respiration ring was measured 3 times and the measurement time was 4 min.

\section{Data analyses}

One-way ANOVA was used to analyse differences in soil temperature, soil volumetric water, and soil respiration of the four reconstructed soils. All statistical tests were carried out using SPSS software (version 16.0; SPSS Inc., Chicago, IL, USA). Nonlinear regression was used to assess the relationship between soil respiration and hydrothermal influence factors of the four reconstructed soils, and $\mathrm{Q}_{10}$ was estimated. The relationship between soil respiration and soil temperature was fitted by an exponential model (Eq.l) and the relationship between soil respiration and water content was fitted by a quadratic curve model (Eq.2). Additionally, the relationship between soil respiration and both soil temperature and soil volumetric water content was fitted by a power-index model (Eq.3):

$$
\begin{gathered}
R_{S}=a \mathrm{e}^{b T}, Q_{10}=\mathrm{e}^{10 b} \\
R_{\mathrm{S}}=a \mathrm{w}^{2}+b \mathrm{w}+c \\
R_{\mathrm{S}}=a \mathrm{e}^{b \mathrm{~T}} \mathrm{w}^{c}
\end{gathered}
$$

where $R_{S}$ is the soil respiration rate $\left(\mu \mathrm{mol} \mathrm{m} \mathrm{m}^{-2} \mathrm{~s}^{-1}\right) ; T$ is the soil temperature $\left({ }^{\circ} \mathrm{C}\right) ; w$ is the soil volumetric water content $(\%) ; a, b$, and $c$ are the model parameters, and $Q_{10}$ is the sensitivity coefficient of soil respiration, which refers to the change in entropy of soil respiration rate when the soil temperature rises by $10^{\circ} \mathrm{C}$.

\section{Results and analysis}

\section{Diurnal variation in the respiration of reconstructed soil masses}

Diurnal variation in the respiration of four reconstructed soil masses showed a single-peak curve and the lowest value appeared at 6:00 or 20:00. In contrast, the highest value appeared at 10:00, 12:00, or 14:00 in the observed months. This result was mainly influenced by the material properties of reconstructed soil masses, which included meteorite, shale, sand, and soft rock. In the observed months, the diurnal variation in the respiration of four reconstructed soil masses with the addition of meteorite, shale, sand, and soft rock ranged from 0.37 to $3.42 \mu \mathrm{mol} \cdot \mathrm{m}^{-2} \cdot \mathrm{s}^{-1}, 0.52$ to $4.34 \mu \mathrm{mol} \cdot \mathrm{m}^{-2} \cdot \mathrm{s}^{-1}, 0.71$ to $4.62 \mu \mathrm{mol} \cdot \mathrm{m}^{-2} \cdot \mathrm{s}^{-1}$, and 0.55 to $4.03 \mu \mathrm{mol} \cdot \mathrm{m}^{-2} \cdot \mathrm{s}^{-1}$, respectively. The order of diurnal variation in the respiration of four reconstructed soil masses was as follows: sand> shale > soft rock > meteorite (Fig. 1). 


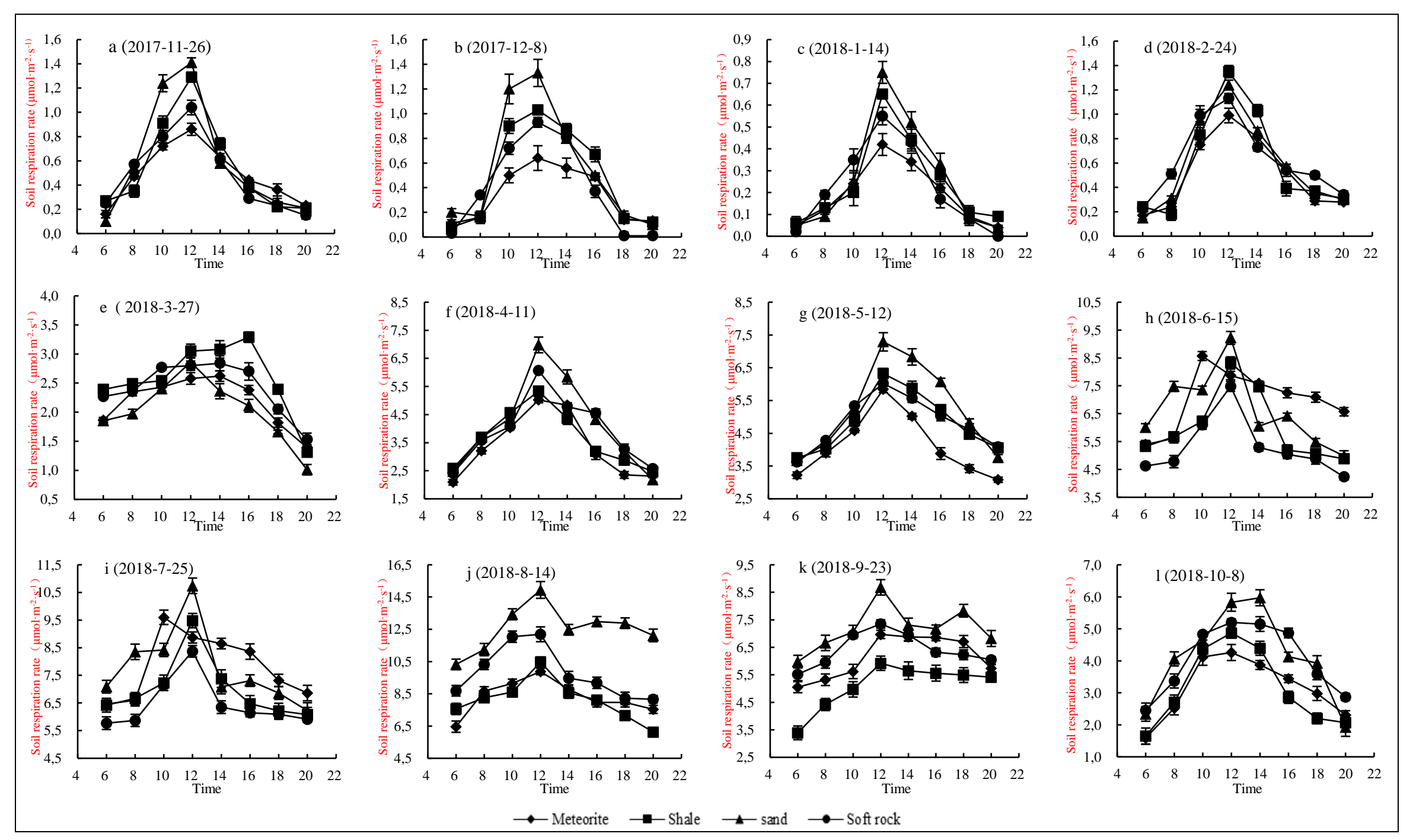

Figure 1. Diurnal variation in respiration, per month, of the four reconstructed soil masses 
In November and December, the temperature was lower, soil microorganisms and crops were dormant, soil respiration rate in the four reconstructed soil masses was low, and the diurnal variation was insignificant. In November, the minimum soil respiration rate in the reconstructed soil masses, modified by adding meteorite, shale, sand, and soft rock, was $0.16 \mu \mathrm{mol} \cdot \mathrm{m}^{-2} \cdot \mathrm{s}^{-1}, 0.21 \mu \mathrm{mol} \cdot \mathrm{m}^{-2} \cdot \mathrm{s}^{-1}, 0.10 \mu \mathrm{mol} \cdot \mathrm{m}^{-2} \cdot \mathrm{s}^{-1}$, and $0.15 \mu \mathrm{mol} \cdot \mathrm{m}^{-2} \cdot \mathrm{s}^{-1}$, respectively. The maximum values for all reconstructed soil masses appeared at 12:00 (Fig. 1a). In December, the minimum soil respiration rate in reconstructed soil masses modified by adding meteorite, shale, sand, and soft rock was $0.11 \mu \mathrm{mol} \cdot \mathrm{m}^{-2} \cdot \mathrm{s}^{-1}$, $0.08 \mu \mathrm{mol} \cdot \mathrm{m}^{-2} \cdot \mathrm{s}^{-1}, 0.1 \mu \mathrm{mol} \cdot \mathrm{m}^{-2} \cdot \mathrm{s}^{-1}$, and $0 \mu \mathrm{mol} \cdot \mathrm{m}^{-2} \cdot \mathrm{s}^{-1}$, respectively. The maximum values for all reconstructed soil masses appeared at 12:00 (Fig. 1b).

In January, the atmospheric temperature reached the minimum value of the year, and the physiological activities of crops and microorganisms stopped. Similarly, the respiration values of reconstructed soil masses reached the lowest during the observation period, and the diurnal variation was also the smallest. The minimum respiration rate in the reconstructed soil masses modified by adding meteorite, shale, sand, and soft rock was $0.04 \mu \mathrm{mol} \cdot \mathrm{m}^{-2} \cdot \mathrm{s}^{-1}, 0.06 \mu \mathrm{mol} \cdot \mathrm{m}^{-2} \cdot \mathrm{s}^{-1}, 0.04 \mu \mathrm{mol} \cdot \mathrm{m}^{-2} \cdot \mathrm{s}^{-1}$, and 0 $\mu \mathrm{mol} \cdot \mathrm{m}^{-2} \cdot \mathrm{s}^{-1}$, respectively. The maximum values were all recorded at $12: 00$, and the daily variation ranges were $0.37 \mu \mathrm{mol} \cdot \mathrm{m}^{-2} \cdot \mathrm{s}^{-1}, 0.59 \mu \mathrm{mol} \cdot \mathrm{m}^{-2} \cdot \mathrm{s}^{-1}, 0.71 \mu \mathrm{mol} \cdot \mathrm{m}^{-2} \cdot \mathrm{s}^{-1}$, and $0.55 \mu \mathrm{mol} \cdot \mathrm{m}^{-2} \cdot \mathrm{s}^{-1}$, respectively (Fig. 1 c).

In February, the temperature began to rise, crops and microorganisms began to recover, and soil respiration in the four reconstructed soil masses also began to rise. The minimum soil respiration in the reconstructed soil masses, modified by adding meteorite, shale, sand, and soft rock, was $0.17 \mu \mathrm{mol} \cdot \mathrm{m}^{-2} \cdot \mathrm{s}^{-1}, 0.24 \mu \mathrm{mol} \cdot \mathrm{m}^{-2} \cdot \mathrm{s}^{-1}, 0.15$ $\mu \mathrm{mol} \cdot \mathrm{m}^{-2} \cdot \mathrm{s}^{-1}$, and $0.23 \mu \mathrm{mol} \cdot \mathrm{m}^{-2} \cdot \mathrm{s}^{-1}$, respectively. The maximum values were all recorded at 12:00 (Fig. 1d).

In March, April, and May, soil respiration rate in the four reconstructed soil masses continued to increase. Specifically, the maximum soil respiration, in March, was $2.62 \mu \mathrm{mol} \cdot \mathrm{m}^{-2} \cdot \mathrm{s}^{-1}, \quad 3.08 \mu \mathrm{mol} \cdot \mathrm{m}^{-2} \cdot \mathrm{s}^{-1}, \quad 2.86 \mu \mathrm{mol} \cdot \mathrm{m}^{-2} \cdot \mathrm{s}^{-1}$, and $2.84 \mu \mathrm{mol} \cdot \mathrm{m}^{-2} \cdot \mathrm{s}^{-1}$, respectively. The minimum values were all recorded at 20:00 (Fig. le). In contrast, the maximum soil respiration in April was $5.02 \mu \mathrm{mol} \cdot \mathrm{m}^{-2} \cdot \mathrm{s}^{-1}, 5.33 \mu \mathrm{mol} \cdot \mathrm{m}^{-2} \cdot \mathrm{s}^{-1}$, $6.98 \mu \mathrm{mol} \cdot \mathrm{m}^{-2} \cdot \mathrm{s}^{-1}$, and $6.06 \mu \mathrm{mol} \cdot \mathrm{m}^{-2} \cdot \mathrm{s}^{-1}$, respectively. The minimum values for all reconstructed soil masses were recorded at 12:00 (Fig. 1f). While, in May, the maximum soil respiration rate was $5.84 \mu \mathrm{mol} \cdot \mathrm{m}^{-2} \cdot \mathrm{s}^{-1}, 6.32 \mu \mathrm{mol} \cdot \mathrm{m}^{-2} \cdot \mathrm{s}^{-1}, 7.29 \mu \mathrm{mol} \cdot \mathrm{m}^{-}$ ${ }^{2} \cdot \mathrm{s}^{-1}$, and $6.02 \mu \mathrm{mol} \cdot \mathrm{m}^{-2} \cdot \mathrm{s}^{-1}$, respectively, and the minimum values were recorded at 6:00 or 20:00 (Fig. 1 g).

In June and July, the soil respiration rate in the four reconstructed soil masses continued to increase, and the minimum value for all soil masses appeared at 6:00 or 12:00. In June, the maximum soil respiration rate was $8.57 \mu \mathrm{mol} \cdot \mathrm{m}^{-2} \cdot \mathrm{s}^{-1}$, $8.32 \mu \mathrm{mol} \cdot \mathrm{m}^{-2} \cdot \mathrm{s}^{-1}, 9.22 \mu \mathrm{mol} \cdot \mathrm{m}^{-2} \cdot \mathrm{s}^{-1}$, and $7.48 \mu \mathrm{mol} \cdot \mathrm{m}^{-2} \cdot \mathrm{s}^{-1}$ (Fig. 1h); In July, the maximum soil respiration rate in reconstructed soil masses was $9.60 \mu \mathrm{mol} \cdot \mathrm{m}^{-2} \cdot \mathrm{s}^{-1}$, $9.48 \mu \mathrm{mol} \cdot \mathrm{m}^{-2} \cdot \mathrm{s}^{-1}, 10.74 \mu \mathrm{mol} \cdot \mathrm{m}^{-2} \cdot \mathrm{s}^{-1}$, and $8.37 \mu \mathrm{mol} \cdot \mathrm{m}^{-2} \cdot \mathrm{s}^{-1}$, with the addition of meteorite, shale, sand, and soft rock respectively (Fig. $1 i$ ).

At the peak of the crop season, i.e., in August, the atmospheric temperature was high, and the rainfall was abundant. The respiration values of reconstructed soil masses reached the maximum. This maximum was recorded at 12:00, while the minimum was recorded at 6:00 or 20:00. The maximum respiration rate in reconstructed soil masses was $9.88 \mu \mathrm{mol} \cdot \mathrm{m}^{-2} \cdot \mathrm{s}^{-1}, 10.47 \mu \mathrm{mol} \cdot \mathrm{m}^{-2} \cdot \mathrm{s}^{-1}, 14.94 \mu \mathrm{mol} \cdot \mathrm{m}^{-2} \cdot \mathrm{s}^{-1}$, and $12.19 \mu \mathrm{mol} \cdot \mathrm{m}^{-2} \cdot \mathrm{s}^{-1}$ for soil masses with the meteorite, shale, sand, and soft rock, respectively. The extent of 
daily variation was $3.42 \mu \mathrm{mol} \cdot \mathrm{m}^{-2} \cdot \mathrm{s}^{-1}, 4.34 \mu \mathrm{mol} \cdot \mathrm{m}^{-2} \cdot \mathrm{s}^{-1}, 4.62 \mu \mathrm{mol} \cdot \mathrm{m}^{-2} \cdot \mathrm{s}^{-1}$, and $4.03 \mu \mathrm{mol} \cdot \mathrm{m}^{-2} \cdot \mathrm{s}^{-1}$, respectively (Fig. $1 \mathrm{j}$ ).

In September and October, the soil respiration rate in the four reconstructed soil masses continued to decrease, and the maximum value for all soil masses was recorded at 12:00. Specifically, the minimum respiration rate of reconstructed soil masses in September was $5.05 \mu \mathrm{mol} \cdot \mathrm{m}^{-2} \cdot \mathrm{s}^{-1}, 3.39 \mu \mathrm{mol} \cdot \mathrm{m}^{-2} \cdot \mathrm{s}^{-1}, 5.98 \mu \mathrm{mol} \cdot \mathrm{m}^{-2} \cdot \mathrm{s}^{-1}$, and 5.52 $\mu \mathrm{mol} \cdot \mathrm{m}^{-2} \cdot \mathrm{s}^{-1}$ for soil masses with the meteorite, shale, sand, and soft rock, respectively. The minimum values were recorded at 6:00 (Fig. $1 \mathrm{k}$ ). In October, the minimum respiration rate of reconstructed soil masses was $1.59 \mu \mathrm{mol} \cdot \mathrm{m}^{-2} \cdot \mathrm{s}^{-1}, 1.65 \mu \mathrm{mol} \cdot \mathrm{m}^{-2} \cdot \mathrm{s}^{-1}$, $1.93 \mu \mathrm{mol} \cdot \mathrm{m}^{-2} \cdot \mathrm{s}^{-1}$, and $2.45 \mu \mathrm{mol} \cdot \mathrm{m}^{-2} \cdot \mathrm{s}^{-1}$ for soil masses with the meteorite, shale, sand, and soft rock, and the minimum values appeared at 6:00 or 20:00 (Fig. 1l).

\section{Hydrothermal factors influencing the diurnal variation in reconstructed soil masses}

The diurnal variation in temperature in the four reconstructed soil masses showed a single-peak curve. The trend in the diurnal variation of temperature, in different months, in the four reconstructed soil masses was about the same. The maximum temperature was recorded at 10:00, 12:00, or 14:00. In contrast, the minimum temperature was recorded at 6:00 or 20:00. The temperature in the reconstructed soil masses with sand was the highest in each month, while the reconstructed soil masses with meteorite had the lowest temperature in each month. During the observation months, the maximum temperature range of the reconstructed soil masses, with the meteorite, shale, sand, and soft rock, was $1.77-29.94^{\circ} \mathrm{C}, 1.87-30.56^{\circ} \mathrm{C}, 2.01-32.34^{\circ} \mathrm{C}$, and $1.84-32.36^{\circ} \mathrm{C}$, respectively. In contrast, the minimum temperature range was $0.27-27.02^{\circ} \mathrm{C}, 0.41-$ $27.72^{\circ} \mathrm{C}, 0.31-29.20^{\circ} \mathrm{C}$, and $0.11-29.26^{\circ} \mathrm{C}$, respectively. The maximum and minimum temperatures were recorded in August and January 2018, respectively.

On the other hand, the maximum range of volumetric water content in reconstructed soil masses, with the meteorite, shale, sand, and soft rock, was 4.2-26.0\%, 3.2-26.3\%, $4.1-26.9 \%$, and 5.9-26.1\%, respectively. While, the minimum range was $1.3-23.12 \%$, $1.5-23.42 \%, 0.2-23.02 \%$, and $0.6-23.56 \%$, respectively. The differences in soil volumetric water content among the four reconstructed soil masses were not significant $(p<0.05)$. The maximum and minimum values occurred in June 2018 and November 2017 , respectively.

\section{Diurnal variation relationship between soil respiration and hydrothermal factors}

\section{Relationship between soil respiration and soil temperature}

The exponential model can characterise the diurnal relationship between soil respiration and temperature of the four reconstructed soil masses. There was a significant positive exponential correlation between the soil respiration rate and soil temperature for the four reconstructed soil masses. The temperature of reconstructed soil mass, with the meteorite, shale, sand, and soft rock, can explain the diurnal variation of soil respiration by $41.0 \%-96.0 \%, 53.0 \%-98.0 \%, 76.0 \%-98.0 \%$, and $66.0 \%-96.0 \%$, respectively (Table 1). The temperature of reconstructed soil masses with sand and meteorite had the highest and lowest explanatory capability, respectively, for the diurnal variation in soil respiration. 
Table 1. Relationship between soil respiration rate and temperature for reconstructed soil masses $\left(R_{S}=a e^{b T}\right)$

\begin{tabular}{c|c|c|c|c|c|c|c|c|c}
\hline \multirow{2}{*}{ Date } & \multicolumn{3}{|c|}{ meteorite } & \multicolumn{2}{c|}{ shale } & \multicolumn{2}{c|}{ sand } & \multicolumn{2}{c}{ soft rock } \\
\cline { 2 - 10 } & $\mathbf{a}$ & $\mathbf{b}$ & $\mathbf{R}^{\mathbf{2}}$ & $\mathbf{a}$ & $\mathbf{R}^{\mathbf{2}}$ & $\mathbf{a}$ & $\mathbf{R}^{\mathbf{2}}$ & $\mathbf{a}$ & $\mathbf{R}^{\mathbf{2}}$ \\
\hline $11-26$ & 0.0053 & 0.5971 & 0.85 & 0.0022 & 0.89 & 0.0018 & 0.84 & 0.0041 & 0.94 \\
$12-8$ & 0.0113 & 0.6412 & 0.93 & 0.0009 & 0.98 & 0.0029 & 0.93 & 0.0053 & 0.8 \\
$1-14$ & 0.1054 & 1.6142 & 0.41 & 0.1133 & 0.76 & 0.0704 & 0.86 & 0.0838 & 0.66 \\
$2-24$ & 0.005 & 0.3788 & 0.92 & 0.0012 & 0.84 & 0.0001 & 0.86 & 0.0045 & 0.84 \\
$3-27$ & 0.305 & 0.1296 & 0.49 & 0.2237 & 0.53 & 0.1651 & 0.87 & 0.2925 & 0.9 \\
$4-11$ & 0.5737 & 0.1057 & 0.8 & 0.5862 & 0.96 & 0.4076 & 0.98 & 0.6669 & 0.87 \\
$5-12$ & 0.4896 & 0.1032 & 0.81 & 0.2495 & 0.91 & 0.1836 & 0.94 & 0.5519 & 0.93 \\
$6-15$ & 0.8877 & 0.0836 & 0.61 & 0.6772 & 0.95 & 0.4751 & 0.83 & 0.6433 & 0.74 \\
$7-25$ & 1.07 & 0.0732 & 0.63 & 0.7522 & 0.51 & 0.6225 & 0.76 & 0.6557 & 0.67 \\
$8-14$ & 1.4698 & 0.0674 & 0.6 & 1.3315 & 0.59 & 1.3642 & 0.97 & 1.5094 & 0.96 \\
$9-23$ & 1.0979 & 0.0913 & 0.82 & 0.7797 & 0.59 & 0.7207 & 0.79 & 1.3289 & 0.6 \\
$10-8$ & 0.6334 & 0.0903 & 0.96 & 0.5484 & 0.87 & 0.368 & 0.85 & 0.8892 & 0.81 \\
\hline
\end{tabular}

\section{Relationship between soil respiration and soil volumetric water content}

The quadratic curve model can explain the diurnal relationship between soil respiration and soil volumetric water content for the four reconstructed soil masses. There was significant negative correlation between both soil respiration and soil volumetric water content; however, the explanatory power was significantly lower than the soil temperature. The volumetric water content of the reconstructed soil mass, with the meteorite, shale, sand, and soft rock, explained the diurnal variation in soil respiration by $23.0 \%-46.0 \%, 28.0 \%-53.0 \%, 26.0 \%-44.0 \%$, and $24.0 \%-50.0 \%$, respectively (Table 2). The volumetric water content of the reconstructed soil masses with shale and meteorite had the highest and lowest explanatory power, respectively, for diurnal variation in soil respiration.

Table 2. Relationship between soil respiration rate and volumetric water content for reconstructed soil masses $\left(R_{S}=a w^{2}+b w+c\right)$

\begin{tabular}{c|c|c|c|c|c|c|c|c|c|c}
\hline \multirow{2}{*}{ Date } & \multicolumn{4}{|c|}{ meteorite } & \multicolumn{2}{c|}{ shale } & \multicolumn{2}{c|}{ sand } & \multicolumn{2}{c}{ soft rock } \\
\cline { 2 - 10 } & $\mathbf{a}$ & $\mathbf{b}$ & $\mathbf{c}$ & $\mathbf{R}^{\mathbf{2}}$ & $\mathbf{a}$ & $\mathbf{R}^{\mathbf{2}}$ & $\mathbf{a}$ & $\mathbf{R}^{\mathbf{2}}$ & $\mathbf{a}$ & $\mathbf{R}^{\mathbf{2}}$ \\
\hline $11-26$ & -0.0074 & 0.0563 & -0.0002 & 0.23 & -0.2907 & 0.41 & -0.5006 & 0.26 & -0.4018 & 0.37 \\
$12-8$ & -0.3027 & 0.0857 & -0.0138 & 0.27 & -1.2562 & 0.53 & -0.6835 & 0.32 & -0.1040 & 0.26 \\
$1-14$ & -0.2926 & 0.321 & -0.0447 & 0.27 & -2.4507 & 0.49 & -2.4507 & 0.49 & -0.6520 & 0.47 \\
$2-24$ & -1.0419 & 0.2341 & -0.0171 & 0.46 & -1.3107 & 0.34 & -0.4457 & 0.38 & -0.6641 & 0.46 \\
$3-27$ & -4.5251 & 1.5778 & -0.0874 & 0.46 & -1.4536 & 0.36 & -1.7270 & 0.40 & -3.2451 & 0.40 \\
$4-11$ & -7.2434 & 3.9182 & -0.4361 & 0.43 & -9.3423 & 0.37 & -18.921 & 0.29 & -11.501 & 0.38 \\
$5-12$ & -16.848 & 3.9518 & -0.2945 & 0.46 & -2.1421 & 0.40 & -9.8838 & 0.44 & -7.6091 & 0.44 \\
$6-15$ & -3.8989 & 1.0745 & -0.0794 & 0.33 & -5.1743 & 0.28 & -4.0945 & 0.41 & -6.4708 & 0.24 \\
$7-25$ & -8.4506 & 0.0718 & -0.0391 & 0.37 & -8.2741 & 0.42 & -8.3395 & 0.29 & -6.2462 & 0.40 \\
$8-14$ & -5.2308 & 0.6053 & -0.0220 & 0.31 & -8.5168 & 0.31 & -13.644 & 0.29 & -17.665 & 0.49 \\
$9-23$ & -5.1123 & 0.2868 & -0.0130 & 0.38 & -4.4172 & 0.53 & -4.9809 & 0.37 & -8.5975 & 0.45 \\
$10-8$ & -1.4618 & 0.7283 & -0.0577 & 0.46 & -5.5392 & 0.39 & -0.8546 & 0.23 & -3.4286 & 0.5 \\
\hline
\end{tabular}




\section{Relationship between soil respiration and temperature, volumetric water content}

The power-exponential model was sufficient to characterise the diurnal relationship between soil respiration and temperature, volumetric water content, of the four reconstructed soil masses. The results showed significant positive correlation between the respiration and both factors. Temperature and volumetric water content of the reconstructed soil masses, with the meteorite, shale, sand, and soft rock, explained the daily variation in soil respiration by $56.0 \%-94.0 \%, 67.0 \%-53.0 \%, 83.0 \%-98.0 \%$, and $56.0 \%-99.0 \%$, respectively (Table 3 ). The two factors of temperature and volumetric water content for reconstructed soil masses with sand and meteorite had the highest and lowest explanatory capability, respectively, of the diurnal variation in soil respiration.

Table 3. Relationship between soil respiration rate and hydrothermal factors for reconstructed soil masses $\left(R_{S}=a e^{b T} w^{c}\right)$

\begin{tabular}{c|c|c|c|c|c|c|c|c|c|c}
\hline \multirow{2}{*}{ Date } & \multicolumn{4}{|c|}{ meteorite } & \multicolumn{2}{c|}{ shale } & \multicolumn{2}{c|}{ sand } & \multicolumn{2}{|c}{ soft rock } \\
\cline { 2 - 10 } & $\mathbf{a}$ & $\mathbf{b}$ & $\mathbf{c}$ & $\mathbf{R}^{\mathbf{2}}$ & $\mathbf{a}$ & $\mathbf{R}^{\mathbf{2}}$ & $\mathbf{a}$ & $\mathbf{R}^{\mathbf{2}}$ & $\mathbf{a}$ & $\mathbf{R}^{\mathbf{2}}$ \\
\hline $11-26$ & 0.009 & 0.515 & 0.072 & 0.9 & 0.001 & 0.91 & 0.001 & 0.93 & 0.004 & 0.99 \\
$12-8$ & 0.032 & 0.602 & 0.412 & 0.91 & 0.002 & 0.98 & 0.003 & 0.99 & 0.002 & 0.93 \\
$1-14$ & 0.142 & 1.053 & 0.034 & 0.56 & 0.031 & 0.92 & 0.040 & 0.95 & 1.315 & 0.56 \\
$2-24$ & 0.013 & 0.407 & 0.207 & 0.91 & 0.001 & 0.88 & 0.001 & 0.95 & 0.005 & 0.87 \\
$3-27$ & 0.052 & 0.236 & 0.118 & 0.75 & 0.001 & 0.90 & 0.020 & 0.85 & 0.486 & 0.92 \\
$4-11$ & 0.020 & 0.328 & 0.036 & 0.97 & 0.056 & 0.99 & 0.067 & 0.93 & 0.122 & 0.97 \\
$5-12$ & 0.032 & 0.228 & 0.022 & 0.92 & 0.027 & 0.88 & 0.007 & 0.98 & 0.079 & 0.95 \\
$6-15$ & 0.322 & 0.120 & 0.060 & 0.87 & 0.103 & 0.98 & 0.113 & 0.97 & 0.055 & 0.87 \\
$7-25$ & 0.250 & 0.126 & 0.074 & 0.90 & 0.162 & 0.90 & 0.432 & 0.68 & 0.668 & 0.72 \\
$8-14$ & 0.994 & 0.076 & 0.083 & 0.77 & 0.127 & 0.91 & 0.737 & 0.97 & 0.186 & 0.93 \\
$9-23$ & 0.003 & 0.388 & 0.006 & 0.94 & 0.009 & 0.67 & 0.111 & 0.86 & 0.018 & 0.95 \\
$10-8$ & 0.109 & 0.189 & 0.016 & 0.85 & 0.021 & 0.89 & 0.038 & 0.83 & 0.068 & 0.90 \\
\hline
\end{tabular}

\section{Discussion}

\section{Effects of different reconstructed materials on soil respiration}

Sixty types of mineral materials have been studied locally and globally for improving soil quality, and a series of improved products have been formed, such as mineral fertilisers, growth agents, and nutrient carriers. The additive materials selected in this study were mineral materials, which have natural and unique crystal structures and good physical and chemical characteristics. They have the advantage of improving soil structure, improving soil water retention capacity, increasing soil fertility, adjusting soil $\mathrm{pH}$, and repairing heavy metal pollution (Wen, 2014; Zhang et al., 2016; Sun et al., 2018). The addition of the improved materials changed the physical and chemical properties of the reconstructed soil masses and the ecological environment at the study area (Lin et al., 2016; Wang et al., 2018). This caused the changes in the gas and material cycle processes to affect the soil activity of plant root microorganisms (Keiluweit, 2015). Consequently, this has an effect on soil respiration in reconstructed soil masses.

Properties of different reconstructed materials may cause differences in soil respiration and soil respiration intensity, which was not conducive to environmental protection. The temperature in the reconstructed soil masses, with the addition of sand, 
was the highest in each month. The temperature of the reconstructed soil masses with meteorite was the lowest in each month. The order of the diurnal variation in the respiration of the four reconstructed soil masses was as follows: sand > shale > soft rock $>$ meteorite, respectively, over the observed months. This is mainly due to the difference in specific heat capacity. The meteorite has excellent water retention performance, and the sand heats up faster as it is closer to the air temperature. Once the sand and the ambient temperature are consistent, heat conduction will no longer occur. The meteorite takes a long time to heat up due to the large specific heat capacity; thus, the adjacent sand temperature decreases rapidly. Soft rock and shale with high clay content can be used as soil-forming materials. In contrast, meteorite can be used as modified material. Simultaneously, these three materials can increase soil water retention. The water occupied the soil gap, resulting in relatively low $\mathrm{CO}_{2}$ content in the soil, and the soil respiration was low. Therefore, this was conducive to environmental protection. Meanwhile, sand, as a soil improvement material, can increase the $\mathrm{CO}_{2}$ content in the soil and soil respiration intensity, thus leading to non-conducive conditions for environmental protection.

\section{Relationship between respiration and hydrothermal factors of reconstructed soil masses}

The diurnal changes in the soil respiration in the four reconstructed soil masses showed a single-peak curve, and the patterns of diurnal changes in respiration were similar for different months. This result is consistent with the study of Fu et al. (2019) and Shi et al. (2012a) conducted in the farmland of the Western Sichuan Plain and Platycladus orientalis forest on the Loess Plateau of the arid and semi-arid region, respectively. However, in Cui et al. (2016), the soil respiration patterns differed per month, and not all of them showed a single-peak curve. This finding may be caused by the differences in the study area, management measures (i.e., artificial), and soil-grown crops (Li, 2014b; Zhou, 2014). The maximum and minimum soil respiration values were recorded at 10:00 - 16:00 and 03:00 - 05:00 (Zhao et al., 2014), 12:00 - 16:00, and 6:00 (Shi et al., 2012b), 12:00 - 15:00, 2:00 - 6:00 (Fu et al., 2019). The test observation showed that the lowest value was recorded at 6:00 or 20:00, while the highest value was recorded at 10:00, 12:00, or 14:00. This finding indicates that the maximum and minimum values of the diurnal soil respiration changed after adding different materials. However, the results are consistent with previous studies. The soil respiration values of the four reconstructed soil masses reached the maximum and minimum in August and January, respectively. Moreover, the diurnal variation was the smallest in January. This finding is consistent with Tu et al. (2015). This variation was caused by the growth of vegetation and changes in seasonal climatic factors (Kuzyakov et al., 2010; Wang et al., 2015). In summer, the soil temperature and humidity conditions are high, the root system is enhanced, the soil microbial metabolism is strong, and the decomposition of organic matter is also enhanced (Fang et al., 2015; Yu et al., 2019). These conditions promote soil respiration.

Among the many factors affecting soil respiration rate, studies show that temperature is the most vital factor. Moreover, soil temperature can indirectly affect soil respiration by affecting plant roots and soil microbial activity (Fu et al., 2012, 2018). The lowest and highest value of the reconstructed soil masses appeared in January and August, respectively. This is because the soil temperature is the process of absorbing and releasing energy according to changes in the solar radiation and atmospheric 
temperature. It is affected by solar radiation balance, soil heat balance, and soil temperature change with air temperature. Therefore, the temperature can also be a good indicator of soil respiration in different climates (Zhang et al., 2013). However, the maximum value in soil respiration sometimes lags, mainly because the soil temperature does not show high peak that is consistent with the air temperature but lags behind it (Qin and Shang-guan, 2012). The exponential model explained most of the variability in soil respiration rate (Zhang et al., 2013, 2014). This study found that the diurnal respiration in the four reconstructed soil masses was significantly positively correlated with soil temperature. The conclusions are, therefore, the same as previous studies.

Water is one of the necessary conditions for plant life. Soil texture and structure affect the water dynamics. Due to the different topographical conditions of the underlying surface, the soil texture, and the crop types, the depth and water absorption of the root system are also different, and there is also a vertical variation in the spatial distribution of soil moisture (Zhu et al., 2019). Under different surface conditions, the spatial variability of soil moisture distribution is vast. Even if the differences in underlying surface conditions were minimal, the unevenness of soil moisture distribution was widespread, and the soil moisture content had an apparent variability. This is consistent with the conclusion that the water volume in the reconstructed soil masses has a significant variation after adding different materials. The effect of soil volumetric water content on soil respiration is complicated. The conclusions by scholars in different regions, research periods, and ecosystems are often inconsistent (Ma et al., 2016; Ding et al., 2017). In addition to root growth and microbial activity, soil volumetric water content can also affect soil respiration rate by affecting soil $\mathrm{CO}_{2}$ content and transmission process (Wang et al., 2007, 2014). The relationship between soil volumetric water content and soil respiration can be simulated by the logarithmic model, quadratic curve, and linear relationship (Geng et al., 2012). Soil volumetric water content and soil respiration were significantly negatively correlated ( $\mathrm{Tu}$ et al., 2015; Duan et al., 2018). Some studies show that when soil moisture stress occurs, water can be a dominant factor affecting soil respiration (Kosugi et al., 2007; Wang et al., 2014). This study found that the quadratic curve can characterise the relationship between volumetric water content and soil respiration. However, the correlation coefficient and the effect on soil respiration were minimal.

Temperature and moisture are the critical environmental factors for the diurnal change of soil respiration. Generally, both soil temperature and soil humidity affect the soil respiration intensity. Therefore, the combination of the two can be used to characterise the diurnal change in soil respiration (Shi et al., 2012b; Li et al., 2014a). This study fitted the relationship between soil respiration and soil temperature using an exponential model. In contrast, the relationship between soil respiration and soil water content was fitted with a quadratic curve model; and, soil respiration and soil hydrothermal factors were simulated using a power-exponential model. However, the power-exponential model has an explanatory power of more than 56\%, and its interpretation ability was much higher than that of the quadratic curve model. In most cases, the power-exponential model had higher explanatory power than the exponential model. Wang et al. (2006) studied soil respiration in six ecosystems in China's temperate forests. They found that the explanatory power of the two-factor model was usually higher than that of the single-factor model. Moreover, the explanatory power was generally higher than 50\%. In another study, Tu et al. (2015) studied the soil respiration in Platycladus orientalis plantation in Xishan, Beijing. They obtained 
power-exponential model that can better describe the response of soil respiration rate to soil hydrothermal factors, with an explanatory power of $86.8 \%$. Previous studies achieved similar conclusions to the current study.

\section{Conclusions}

(1) The daily variation in the respiration of four reconstructed soil masses showed a single-peak curve, and the pattern of respiratory diurnal changes was basically the same. The lowest value appeared at 6:00 or 20:00 in the observed months, and the highest value appeared at 10:00, 12:00, or 14:00. The soil respiration values of the four reconstructed soil masses reached the maximum and minimum in August and January, respectively. The order of diurnal variation in the respiration of four reconstructed soil masses was as follows: sand > shale > soft rock > meteorite.

(2) The diurnal variation in the respiration of four reconstructed soil masses can be explained by a single factor of soil temperature (i.e., index model), soil volumetric water content (i.e., quadratic model), or both factors (i.e., power-index model). However, the explanatory power was different, i.e., generally higher than $50.0 \%$ for the two-factor model, and the interpretation ability of temperature was significantly higher than that of water for the single-factor model. The model involving both factors were the best to characterize the relationship between hydrothermal influence factors and respiration of four reconstructed soil masses.

(3) This study concludes that the respiration in the reconstructed soil masses was different according to the added materials; thus, the corresponding carbon emissions were also different. The reconstructed soil with meteorite was conducive to the protection of the ecological environment. In this context, the government should add materials that are conducive to environmental protection to reduce $\mathrm{CO}_{2}$ emissions when implementing land remediation. When formulating regional ecological policies, $\mathrm{CO}_{2}$ emissions in restructured soil masses should also be considered to ensure accurate regional measures.

(4) This study analysed the diurnal dynamics in respiration from the reconstructed soil masses and its relationship with hydrothermal factors. The relationship between microbes in the reconstructed soil masses and physicochemical properties with soil respiration should be studied in the future, as well as the main factors affecting soil respiration. The quality of reconstructed soil masses should be characterised more rapidly through dynamic monitoring of the soil respiration. Moreover, the influence of biological factors on soil respiration cannot be ignored. Therefore, the relationship between biological factors and soil respiration should be considered in future studies. Additionally, the carbon emissions from the reconstructed soil masses, as one of the regional carbon emission sources, should be quantified to support accurate regional emission reduction measures.

Acknowledgements. This study was supported by Shaanxi Provincial Land Engineering Construction Group, China, Project No. DJNY2019-20; Industry of Ministry of Water Resources Public Welfare Profession, China, Project No. 201501049. 


\section{REFERENCES}

[1] Cui, H., Zhang, Y. H. (2016): Diurnal and seasonal dynamic variation of soil respiration and its influencing factors of different fenced enclosure years in desert steppec. Environmental Science 37: 331-339.

[2] Ding, X. Y., Wang, Z. K., Yang, X., Du, S. S., Shen, Y. Y. (2017): Response of dry land soil respiration to conservation tillage practices during drying-wetting cycles. - Scientia Agricultura Sinica 50: 4759-4768.

[3] Duan, B. X., Man, X. L., Song, H., Liu, J. L. (2018): Soil respiration and its component characteristics under different types of Larix gmelinii forests in the north of Daxing'an Mountains of northeastern China. - Journal of Beijing Forestry University 40: 40-50.

[4] Fang, H. J., Cheng, S. L., Lin, E. D., Yu, G. R., Niu, S. L., Wang, Y. S., Xu, M. J., Dang, X. S., Li, L. S., Wang, L. (2015): Elevated atmospheric carbon dioxide concentration stimulates soil microbial activity and impacts water extractable organic carbon in an agricultural soil. - Biogeochemistry 122: 253-267.

[5] Fu, G., Shen, Z. X., Zhang, X. Z., Zhou, Y. T. (2012): Response of soil microbial biomass to short-term experimental warming in alpine meadow on the Tibetan Plateau. - Applied Ecology and Environmental Research 61: 158-160.

[6] Fu, G., Shen, Z. X., Zhang, X. Z. (2018): Increased precipitation has stronger effects on plant production of an alpine meadow than does experimental warming in the Northern Tibetan Plateau. - Agricultural and Forest Meteorology 249: 11-21.

[7] Fu, Y., Wang, T., Yang, Z. P., Zhou, W., Liu, Q., Ren, W. J., Chen, Y. (2019): Annual soil respiration characteristics of different paddy-upland rotations in irrigation areas of the Western Sichuan Plain. - Acta Ecologica Sinica 39: 6701-6709.

[8] Geng, Y., Wang, Y., Yang, K., Wang, S., Wang, H., Zeng, H., Baumann, F., Kuehn, P., Scholten, T., He, J. (2012): Soil respiration in Tibetan alpine grasslands: belowground biomass and soil moisture, but not soil temperature, best explain the large-scale patterns. - Plos One 7: e34968.

[9] Goldberg, S. D., Zhao, Y., Harrison, R. D., Monkai, J., Li, Y., Chau, K., Xu, J. (2017): Soil respiration in sloping rubber plantations and tropical natural forests in Xishuangbanna, China. - Agriculture, Ecosystems \& Environment 249: 237-246.

[10] Hu, S. D., Li, Y. F., Chang, S. X., Li, Y. C., Yang, W. J., Fu, W. J., Liu, J., Jiang, P. K., Lin, Z. W. (2018): Soil autotrophic and heterotrophic respirations respond differently to landuse change and variations in environmental factors. - Agricultural and Forest Meteorology 250-251: 290-298.

[11] Keiluweit, M., Bougoure, J. J., Nico, P. S., Pett-Ridge, J., Weber, P. K., Kleber, M. (2015): Mineral protection of soil carbon counteracted by root exudates. - Nature Climate Change 5: 588-595.

[12] Kosugi, Y., Mitani, T., Itoh, M., Noguchi, S., Tani, M., Matsuo, N., Takanashi, S., Ohkubo, S., Nik, A. R. (2007): Spatial and temporal variation in soil respiration in a Southeast Asian tropical rainforest. - Agricultural and Forest Meteorology 147: 35-47.

[13] Kuzyakov, Y., Gavrichkova, O. (2010): Time lag between photosynthesis and carbon dioxide efflux from soil: a review of mechanisms and controls. - Global Change Biology 16: 3386-3406.

[14] Lai, L. M., Jiang, L. H., Wang, Y. J., Zheng, Y. R., Chen, X., Rimmington, G. M. (2012): Soil respiration in different agricultural and natural ecosystems in an arid region. - Plos One 7: e48011.

[15] Li, H. S., Wang, J. S., Liu, X., Jiang, S. S., Zhang, C. Y., Zhao, X. H. (2014a): Effects and its sustained effect of simulated nitrogen deposition on soil respiration in Pinus tabulaeformis forests in the Taiyue Mountain, China. - Acta Scientiae Circumstantiae 34: 238-249. 
[16] Li, Q., Zhou, D. W., Jin, Y. H., Wang, M. L., Sun, Y. T., Li, G. D. (2014b): Effects of fencing on vegetation and soil restoration in a degraded alkaline grassland in northeast China. - Journal of Arid Land 6: 478-487.

[17] Li, X. D., Guo, D., Zhang, C. P., Niu, D. C., Fu, H., Wan, C. G. (2018): Contribution of root respiration to total soil respiration in a semi-arid grassland on the Loess Plateau, China. - Science of the Total Environment 627: 1209-1217.

[18] Lin, Y. L., Li, Y., Chen, Y. H., Fan, H., Wang, Y. N., Wang, J. J. (2016): Effects adding sand on soil physical and chemical property and corn yield in alkalized solonchak soil. Soil and fertilizer Science in China 53: 119-123.

[19] Ma, H. P., Guo, Q. Q., Li, J. R., Zhou, C. N. (2016): Soil Respiration and Its Affecting Factors Relative to Type of Forest in the Sygera Mountains of Southeast Tibetan Plateau. - Acta Pedologica Sinica 53: 253-260.

[20] Meyer, N., Meyer, H., Welp, G., Amelunga, W. (2018): Soil respiration and its temperature sensitivity $\left(\mathrm{Q}_{10}\right)$ : Rapid acquisition using mid-infrared spectroscopy. Geoderma 323: 31-40.

[21] Qi, J., Shang-guan, Z. P. (2012): Variation characteristics of soil respiration rate in Ulms pumila Robinia pseudociain different forest types of during the growing season. - Journal of Northwest A \& F University (Natural Science Edition) 40: 91-98.

[22] Rey, A., Raimundo, J., Oyonarte, C. (2010): Temporal and spatial variation in soil respiration in two semiarid steppe ecosystems with different degrees of land degradation. - Geophysical Research Abstracts 12: 2451.

[23] Shi, W. Y., Zhang, J. G., Yan, M. J., Guan, J. H., Du, S. (2012a): Diurnal and seasonal dynamics of soil respiration in a Platycladus orientalis forest stand on the semiarid Loess Plateau, China. - Journal of Earth Environment 3: 1144-1148.

[24] Shi, W. Y., Zhang, J. G., Yan, M. J., Norikazu, Y., Sheng, D. (2012b): Seasonal and diurnal dynamics of soil respiration fluxes in two typical forests on the semiarid Loess Plateau of China: temperature sensitivities of autotrophs and heterotrophs and analyses of integrated driving factors. - Soil Biology \& Bio-chemistry 52: 99-107.

[25] Sun, Z. H., Han, J. C. (2018): Effect of soft rock amendment on soil hydraulic parameters and crop performance in Mu Us sandy land, China. - Field Crops Research 222: 85-93.

[26] Sun, S., Lei, H., Chang, S. X. (2019): Drought differentially affects autotrophic and heterotrophic soil respiration rates and their temperature sensitivity. - Biology and Fertility of Soils 55: 275-283.

[27] Tu, Z. H., Pang, Z., Zhao, Y., Zheng, L. W., Yu, X. X., Chen, L. H. (2015): Soil respiration components and their controlling factors in a Platycladus orientalis plantation in west mountain area of Beijing. - Acta Scientiae Circumstantiae 35: 2948-2956.

[28] Wang, C. K., Yang, J. Y., Zhang, Q. Z. (2006): Soil respiration in six temperate forests in China. - Global Change Biology 12: 2103-2114.

[29] Wang, X. G., Zhu, B., Wang, Y. Q., Zheng, X. H. (2007): Soil respiration and its sensitivity to temperature under different land use conditions. - Acta Ecologica Sinica 27: 1960-1967.

[30] Wang, B., Zha, T. S., Jia, X., Wu, B., Zhang, Y. Q., Qin, S. G. (2014): Soil moisture modifies the response of soil respiration to temperature in a desert shrub ecosystem. Biogeosciences 11: 259-268.

[31] Wang, B., Zha, T. S., Jia, X., Gong, J. N. (2015): Microtopographic variation in soil respiration and its controlling factors vary with plant phenophases in a desert-shrub ecosystem. - Biogeosciences 12: 5705-5714.

[32] Wang, Z. G., Bing, Y. L., Song, Z. H., Zhang, J., Cai, Y., Gong, Y. L., Hu, J. J. (2018): Substrate compositions facilitate clay restoration of the simulation study in an opencast coal mine in the eastern steppe of China. - Acta Ecologica Sinica 38: 5865-5875.

[33] Wen, J. (2014): Study on Remediation of Heavy Metal Contaminated Soil by Soft rock. Master Thesis, College of Resources and Environment, Northwest A\&F University and Shaanxi Province. 
[34] Yu, C. Q., Han, F. S., Fu, G. (2019): Effects of 7 years experimental warming on soil bacterial and fungal community structure in the Northern Tibet alpine meadow at three elevations. - Science of total Environment 655: 814-822.

[35] Zhang, D. C., Cai, D. X., Dai, K., Feng, Z., Zhang, X., Wang, X. (2013): Soil respiration and its responses to soil moisture and temperature under different tillage systems in dryland maize fields. - Acta Ecologica Sinica 33: 1916-1925.

[36] Zhang, Q., Lei, H. M., Yang, D. W. (2013): Seasonal variations in soil respiration, heterotrophic respiration and autotrophic respiration of a wheat and maize rotation cropland in the North China Plain. - Agricultural and Forest Meteorology 180: 34-43.

[37] Zhang, C., Niu, D., Hall, S., Wen, H., Li, X., Fu, H., Wan, C., Elser, J. J. (2014): Effects of simulated nitrogen deposition on soil respiration components and their temperature sensitivities in a semiarid grassland. - Soil Biology \& Biochemistry 75: 113-123.

[38] Zhang, T. B., Zhan, X. Y., Kang, Y. H., Wan, S. Q., Feng, H. (2016): Amelioration of high saline-sodic wasteland of takyric solonetz by cropping lycium barbarum with drip irrigation and shallow sand-filled niches. - Transactions of the Chinese Society for Agricultural Machinery 47: 139-149.

[39] Zhao, B. Y., Hong, M., Liang, C. Z., Bao, W. Y., Zhang, J. X. (2014): Effect of fertilization on soil respiration in the Stipa breviflora desert steppe of Inner Mongolia. Chinese Journal of Applied Ecology 25: 687-694.

[40] Zhou, X. B., Zhang, Y. M. (2014): Seasonal pattern of soil respiration and gradual changing effects of nitrogen addition in a soil of the Gurbantunggut Desert, northwestern China. - Atmospheric Environment 85: 187-194.

[41] Zhou, W. P., Shen, W. J., Li, Y. E., Hui, D. F. (2017): Interactive effects of temperature and moisture on composition of the soil microbial community. - European Journal of Soil Science 68: 909-918.

[42] Zhu, X., Shao, M., Liang, Y., Tian, Z. Y., Wang, W., Qu, L. (2019): Mesoscale spatial variability of soil-water content in an alpine meadow on the northern Tibetan Plateau. Hydrological Processes 33: 2523-2534. 